\title{
Gıda katkı maddelerinin sağllk üzerine etkileri
}

\author{
Dilan ÖZGÜNª , Aylin SEYLAM KÜȘÜMLER ${ }^{\mathrm{b}}$
}

\section{ÖZET}

Günümüzde gıda teknolojinin gelişmesine ve beslenme alışkanlıklarının değişimine bağlı olarak çok sayıda ve çeşitlilikte işlenmiş gıda üretilmekte ve tüketilmektedir. Tüketicilerin gıda seçimindeki öncelikleri gıdanın besleyici değeri, güvenirliliği ve kullanım uygunluğu olarak sıralanmaktadır. Tüketicilerin beklentilerine cevap verebilecek gıda üretimini sağlayabilmek için gıda katkı maddelerinin kullanımı kaçınılmaz hale gelmiştir. Gıda katkıları, gıda üretim aşamalarında, belirli amaç ve fonksiyonları yerine getirmek için kullanılmaktadır. Doğal ve yapay çok sayıda gıda katkı maddesi üretimi hızla artmaktadır. Tüketicinin bilinçlendirilmesinde gıdanın etiketi anahtar öneme sahiptir. Bu yolla bilgilenen tüketici sağlığını korumada ve gıda seçiminde kendi tercihini kullanabilmektedir. Bu derlemenin amacı, gıdalarda kullanılan katkı maddelerinin sağlık üzerine etkileri araştırılmıştır.

Anahtar kelimeler: Gıda güvenliği, gıda katkıları, gıda mevzuatı

\section{Effects of food additives on health}

\begin{abstract}
Nowadays, depending on the development of food technology and the change of nutritional habits, a large number and variety of processed foods are produced and consumed. Consumers' priorities in food selection are listed as the nutritional value, safety and suitability of food. The use of food additives has become inevitable in order to provide food production that can meet the expectations of consumers. Food additives are used in food production stages to fulfill certain purposes and functions. Production of many natural and artificial food additives is increasing rapidly. The label of food is the key in raising consumer awareness. The consumer, who is informed in this way, can use his/her own preference in protecting health and choosing food. The purpose of this review is to investigate the effects of additives used in foods on health.
\end{abstract}

Keywords: Food security, food additives, food legislation

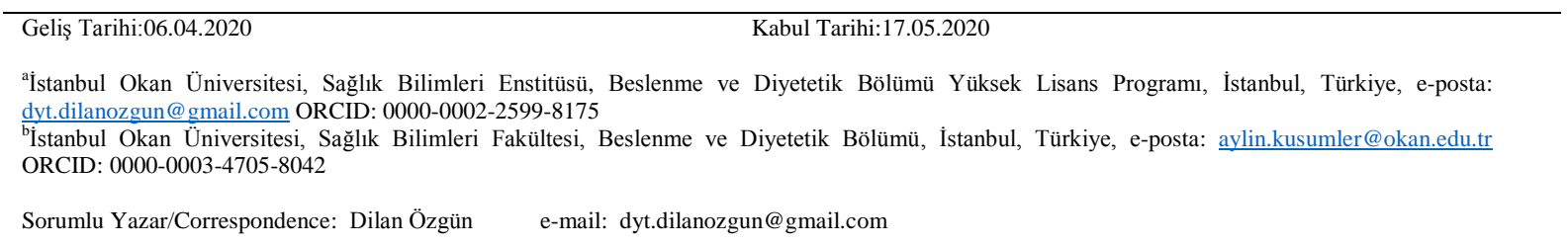




\section{GíRiş}

Gıda güvenliği küresel bir sorundur ve dünya çapında çok sayıda tüketici her yıl çeşitli gıda güvenliği riskleriyle karşı karşıyadır. Son yıllarda, tüketiciler gıda güvenliği konusunda giderek daha bilinçli hale gelmiştir. Gıda katkı maddeleri (GKM); gıda güvenliği ile ilgili en tartışmalı olan maddedir. ${ }^{1}$

GKM, gıdaların kalitesini sağlamak, geliştirmek için uzun yıllardan beri kullanılmaktadır. Tarihsel süreçte, odun tütsüsü ve tuz kullanımının en eski katkı yöntemi olduğu görülmüştür. Şeker, sirke, baharat da ilk kullanılan katkı maddeleri arasındadır. M.Ö 3500 yıllarında eski Mısır'da gıda boyaları, M.Ö. 3000 yıllarında et ürünleri saklamak için tuz, M.Ö. 900 yıllarında odun tütsüsünün ve tuzun gida saklama yöntemi olarak kullanımı görülmektedir. Bunlara ek olarak; Orta çağda etlere nitrat eklenerek mikrobiyolojik bozulmalara ve gida zehirlenmelerine yol açan botulizm önlenmeye çalışılmış ve aynı zamanda nitrat kullanıldığında etin renginin daha sağlıklı göründüğü fark edilmiştir. GKM'nin kullanımı özellikle 18. yüzyılda yaygınlaşmaya başlamıştır. ${ }^{2}$

GKM Türk Gıda Kodeksi G1da Katk1 Maddeleri Yönetmeliği'nde; besleyici değeri olsun veya olmasın, tek başına gıda olarak tüketilmeyen ve gıdanın karakteristik bileşeni olarak kullanılmayan, teknolojik bir amaç doğrultusunda üretilmesi, tasnifi, işleme, hazırlama, ambalajlama, taşıması veya depolaması sırasında gıda maddesinin tat, koku, görünüş, yap1 ve diğer niteliklerini korumak, düzeltmek veya istenmeyen değişikliklere engel olmak amacıyla kullanılmasına izin verilen maddeler olarak tanımlanmaktadır. ${ }^{3}$

\section{Gıda Katkı Maddeleri ve Yasal Düzenlemeler}

Günümüzde toplum yapısı ve beraberinde yiyecek kültürünün hızlı değişimine bağlı olarak GKM üretiminde, çeşidinde ve sayısında önemli derecede artışlar görülmüştür. GKM'nin kontrolsüz ve amacı dışında kullanımı durumunda insan sağlığı olumsuz yönde etkilenir. Hızlı büyüyen g1da sanayisi, gıda katkı maddelerinin kullanımında artışa neden olmuştur ve bu konuda yasal düzenlemelerin yapılmasını gerektirmiştir. GKM'nin özellikleri ve gıdalarda kullanılan miktarları uluslararası düzeyde ele alınan bir konudur. ${ }^{4}$

Birleşmiş Milletler düzeyinde Dünya Sağlık Örgütü (WHO) ve Gıda Tarım Örgütü (FAO)'nün ortaklaşa oluşturduğu Kodeks Alimentarius Komisyonu (CAC)'na bağlı GKM üzerinde çalışan Ortak Uzmanlar Komitesi (JECFA) katk1 maddelerini ilgilendiren konularda önerilerde bulunan bir kuruluştur. CAC tarafından önerilen ilkeler Avrupa
Birliği'ne (EC) bağlı Avrupa Gıda Güvenliği Otoritesi (EFSA) tarafindan da benimsenmiştir. Amerika'da ise GKM konusunda düzenlemeler yapan kurum Gida ve İlaç Dairesi (FDA)'dir. Gıdaların üretiminde kullanılan katkı maddelerinin sağlığı etkilemeyecek işlevde olma zorunluluğu vardır. Bilimsel çalışmalar doğrultusunda WHO ve FDA tarafindan belirtilen GKM'nin günlük kabul edilebilir miktarı dikkate alınarak, her ülkenin gida otoritesi katkı maddesinin katılabileceği gıdayı ve katılma oranlarını kendi ülke koşullarına göre belirlemektedir. ${ }^{5,6}$

Türkiye'de bu belirlemeler uluslararası kuruluşlarca oluşturulan düzenlemeler ve standartların baz alınarak hazırlanan "Türk Gıda Kodeksi Yönetmeliği”ne göre yapılmaktadır. Bu yönetmelikte katkı maddelerinin katılabileceği besinler ve miktarlar belirtilir. ${ }^{7} \mathrm{Bu}$ kimyasal ajanların kontrolsüz ve amacı dışında kullanıldığı iddiaları bunun sonucu toplum sağlığının olumsuz yönde etkilendiği ile ilgili kaygıları ortadan kaldırmak amacıyla başta Birleşmiş Milletler bünyesinde WHO ve FAO iş birliği ile kurulan CAC ve JECFA ile EFSA gibi uluslararası kuruluşlar mevcuttur. ${ }^{8}$

\section{E Kodu ve Uluslararası Numaralandırma Sistemi}

Avrupa Birliğinde kullanıma izin verilen GKM için "Europe" kelimesinin baş harfi olan E harfi kullanılarak numaralandırma işlemi yapılmaktadır. E kodu, toksikolojik araştırmaları tamamlanmış ve zararsızlık dozu belirlenmiş GKM'ye göre verilen uluslararası bir göstergedir.' Her GKM'nin uluslararası kabul edilmiş bir numarası vardır. Örneğin bu numaralardan 621: Monosodyum glutamat (MSG), 330: Sitrik asit, 102: Tartrazin, gibi. ${ }^{10}$ Tablo 1'de kullanım amaçlarına göre gida katk1 maddeleri E kodlarıyla belli başlı gruplara ayrılmıştır. $^{2}$

Tablo 1. Gıda katkı maddelerinin sınıflandırılması

\begin{tabular}{ll}
\hline Gıda katkı maddeleri & E kodları \\
Renklendiriciler & E 100-180 \\
Koruyucular & E 200-285, E 330 \\
Antioksidanlar & E 300-321 \\
Emülsifıyer ve Stabilizatörler & E 322-500 \\
Asit-baz sağlayıcılar & E 500-578 \\
Tatlandırıcılar, koku verenler & E 620-637 \\
Geniş amaçlı GKM & E 900-927 \\
\hline
\end{tabular}

\section{Gıda Katkı Maddelerinin Kullanım Amaçları}

GKM'nin 32 değişik işlevi bulunmaktadır. Bunlar gıda maddelerini tatlandırma, renklendirme veya gıdanın korunması gibi belirli teknolojik işlevlerdir. Hazır gıdalara eklenerek bu amaçlardan bir veya birkaçını yerine getirmek üzere kullanılırlar. ${ }^{2}$ 
GKM'nin kullanım nedenleri aşağıdaki gibi sıralanabilir;

- Gıdanın raf ömrünü uzatması ve kayıpların azalmasını sağlama

- Gidaların duyusal özelliklerini geliştirmesi ve düzeltmesi

- G1dada kalite özelliğini koruması

- Gidaların hazırlanmasına yardımcı olma

- Besleyici değerin korunması. ${ }^{11}$

GKM'nin kullanım amaçlarına göre sınıflandırılması ise aşağıdaki gibi yapılmaktadır;

1. Koruyucular: $\mathrm{Bu}$ katk1 maddeleri besinin kalitesini ve lezzetini koruyarak raf ömrünü uzatırlar. Gidalara eklenen koruyucu gida katkı maddeleri hava, bakteri, küf, mantar ve mayaların neden olduğu bozulmayı yavaşlatır. Koruyucu olarak kullanılan antioksidanlar, yiyeceklerin içindeki katı ve sıvı yağların bayatlamasını veya tadındaki değişiklikleri engellemek amaciyla eklenen koruyucu maddelerdir. $^{12}$

2. Yapıyı ve hazırlama, pişme özelliği geliştirenler: $\mathrm{pH}$ ayarlayıcılar yiyeceklerin tat, lezzet ve renklerine uygun asitlik ve alkali içeriğini değiştirmeye yardımcı olurlar. Gidaların topaklanmasını engelleyen maddeler tuz, süt tozu, pudra şekeri gibi toz halindeki karışımların akışkanlığını korumak için kullanılan maddelerdir. $^{12}$

3. Aromayı ve rengi geliştiriciler: Lezzeti arttırmak veya arzu edilen rengi vererek bazı gıdaların görünüşünü güzelleştirmek amacı ile kullanılır. ${ }^{13}$

4. Besin değerini koruyucu, geliştiriciler: Gıdalar geçtikleri işlemler nedeniyle bazı vitamin ve minerallerin kayıpları oluşabilir ( $\mathrm{B}_{1}, \mathrm{~B}_{2}$, niasin). Ayrıca diyette eksik olan besin öğelerini tamamlamak amaciyla eklenirler (A, D vitaminleri). ${ }^{13}$

\section{Gıda Katkı Maddelerinin Sağlık Üzerine Etkileri}

Gıdalara çeşitli amaçlarla dışarıdan bilinçli olarak katılan gida olmayan kimyasal maddelerin insan sağlığına olumsuz etkileri olduğu görülmüştür. Çok sayıda çalışmada, aşırı miktarda sentetik gıda katk1 maddesi tüketmenin gastrointestinal, solunum, dermatolojik ve nörolojik reaksiyonlara neden olabileceğini saptanmıştır. ${ }^{14}$

\section{Mikrobiyota Üzerine Etkileri}

İnsan sindirim sisteminde yaklaşık 100 trilyon hücre, 10 trilyon somatik hücre ve somatik hücrelerden yaklaşık olarak 10 kat daha fazla mikroorganizma bulunmuştur. Bağırsak mikrobiyotası, insanların sağlığında ve hastalığında oldukça önemli bir yeri vardır. $^{15,16}$ Son yıllarda gıdalara eklenen; başta gıdaların raf ömrünü uzatmak olmak üzere stabilite, tat ve doku geliştirmeye yardımcı olmak için GKM'nin eklenme oranı artmıştır. Çoğunluğu hayvanlar üzerinde olmakla birlikte, GKM ve mikrobiyota arasındaki ilişkiyi saptamak amaçlı birçok çalışma yapılmıştır. $\mathrm{Bu}$ çalışmalarda emülsifiye edici maddelerin ve tatlandırıcıların bağırsak mikrobiyotasının kompozisyonunu değiştirdiği, bağırsak epitelinde bakterilerin translokasyonunu kolaylaştırdığı gösterilmiştir. Karboksimetilselüloz veya polisorbat 80 gibi GKM'nin tüketiminin mukus tabakası kalınlığını belirgin şekilde azalttığı, ülseratif kolit ve Chron hastalığı gibi inflamatuar bağırsak hastalıkları ile kolon kanseri, şişmanlık ve diyabet hastalığında da rolü olduğu düşünülmektedir. ${ }^{17,18}$

\section{Kanser Üzerine Potansiyel Etkileri}

Kürleme; gidaların tat, renk, doku, lezzet ve aromalarının iyileşmesi ve dayanaklığının artması amaciyla tuz, nitrit, nitrat ve baharatlar gibi maddelerin eklenmesidir. ${ }^{19}$ Beslenmede nitrat; genellikle yeşil yapraklı sebzelerden, kürlenmiş et ürünlerinden ve sudan alınmaktadır. ${ }^{20}$ Koruyuculardan en çok ve en sık yan etkisi olan nitrit ve nitrat, et ürünlerinin korunması için kullanılmaktadır. Et ve et ürünlerinde gelişen zararlı bakteri olan Clostridium botulinum'un üremesini engelleyerek, tüketicide olabilecek yüksek toksisiteyi engeller. Clostridium botulinum, insan ve hayvanlar için yüksek toksit etkiye sahip olan en önemli bakteridir. ${ }^{21}$ Nitrit kana geçerek hemoglobinle birleşip methemoglobin oluşturur. Methemoglobin; hemoglobinin oksijen taşıma işlevini önlemektedir. Nitrit ve nitratların nitrozamin gibi kansere neden bileşenlere dönüşebildiği, karaciğer, solunum sistemi, böbrek, idrar kesesi, pankreas, mide gibi pek çok organda aktif hale geçerek kansere neden olurlar. Özellikle çocukluk çağındaki et ve et ürünlerinin tüketimi yüksek düzeyde nitrit ve nitrat tüketimi ile yaşam boyu methemoglobinnemia'ya neden olabilmektedir. $^{14}$

\section{Alerji Üzerine Potansiyel Etkileri}

Doğal gıda bileşenleri ve sonradan ilave edilen gıda katkıları alınan doza ve kişinin özel hassasiyet durumuna bağlı olarak alerjik reaksiyonlara neden olabilir. GKM'nin alımının sonrasında görülen klinik semptomlar anjiyo ödem veya kronik ürtikerdir. Ancak semptomlar ayrica atopik dermatit, kızarma, karın ağrısı, ishal, hipotansiyon ve astım reaksiyonları benzer ağır anafilaktoid ya da şiddetli anafilaktik reaksiyonları içerebilir. ${ }^{22}$ Gida renklendiricileri alerjik reaksiyondan çok, hassas bireylerde direkt farmakolojik etkiyle, ürtikerde prostaglandinler ve histamin salgıladığı düşünülmektedir. Renklendiricilerin özellikle 3-9 yaş arasındaki çocuklarda hiperakivite gibi davranış bozukluğuna neden olduğu rapor edilmiştir. Bu renklendiricilerden 
bazılar1; pantent blue V (E131), tatrazin, allura red, brillant blue (E133), sunset yellow, eritrosin (E127), ponzo 4R ile karmin, karminik asit ve koşinaldir (E120). ${ }^{23}$ Türk Gıda Kodeksi Gıda Katkı Maddeleri Yönetmeliği’ne göre; gıda etiket bilgileri içinde, bazı renklendiriciler için "Renklendirici adı veya E kodu: ilave bilgi" bulunmaktadır. Bu renklendiricilerin bulunduğu besinlerin çocukların aktivite ve dikkatleri üzerinde olumsuz etkileri bulunabileceğgi, ek bilgisi yer almaktadır. ${ }^{3}$

\section{Monosodyum Glutamat}

Monosodyum glutamat (MSG), glutamik asit proteinlerin \%20'sini oluşturan, diyetle alınan peynir, mantar, domates, et ve soya sosu gibi bazı gidalarda doğal olarak bulunan esansiyel olmayan, bir aminoasittir. MSG dünyada en çok bilinen lezzet arttırıcı katkı maddesidir. En çok et ve balık içeren dondurulmuş gıdalar, çoğu konserve gidalarda ve kuru karışım halindeki hazır çorbalarda bulunmaktadır. $^{24}$ Gıdalarda kullanımı deniz yosunlarından elde edilerek antik Çin mutfağına kadar dayanmaktadır. Bu katkı maddesi astım, ürtiker, baş ağrıs1, rinit, psikiyatrik bozukluklar ve konvülziyonlarla ilişkilendirilmiştir. Tat ve koku artırıcı olarak gidalara katılan MSG'a insanlarda hassasiyet olduğu gösterilmiştir. Çin Restaurantı Sendromu olarak bilinen hassasiyette duyu-his kaybı, genel halsizlik ve kalp çarpıntısı eşlik etmektedir. Çin restaurantı sendromu olarak bilinen "sendrom" Çin mutfağında sıklıkla kullanılan MSG’a karşı bazı bireylerdeki idiopatik intolerans olarak tanımlanmaktadir. ${ }^{25}$

MSG; WHO, FAO ve EFSA gibi önemli otoriteler tarafından güvenilir olduğu kabul edilmektedir. Son dönemde yapılan bazı çalışmalarda; fareler üzerinde MSG tüketiminin, obezite ve karaciğer yağlanmasının gelişmesiyle ilişkili olabileceği üzerine bazı sonuçlar elde edilmiştir. Amerika, İtalya ve Japonya'da bir grup araştırmacı tarafından yapılan çalışmada MSG verilen farelerde kilo artışı ve alkole bağlı olmayan karaciğer yağlanması gözlemlenmiştir. Ayrıca MSG miktarının diyette kısıtlanmasının da bu etkileri tamamen yok etmediği ancak karaciğer yağlanmasının ilerleyişini yavaşlattığ 1 da bu çalışmadan elde edilen diğer bir sonuçtur. ${ }^{26}$

\section{SONUÇ}

Dünya nüfusunun artması, değişen beslenme alışkanlıkları, besin çeşitliliğinin çoğalması ve gıda sanayisinin gelişmesine bağlı olarak GKM'nin kullanımı kaçınılmazdır. GKM'nin kullanım amacı, gıdalara mikroorganizma bulaşmasını önlemek, gıdaların raf ömrünü uzatmak, gida değerinin korunmasını sağlamak ve duyusal özellikleri koruyarak gıda içindeki kayıpları önlemektir. GKM'leri bu tür belirli işlevleri yerine getirmek amacıyla gıdalara bilinçli şekilde koyulmaktadır. GKM'nin teknolojik olarak kullanılmasının gerekli olduğu gıdalarda, belirtilen miktarlarda kullanılması sağlık açısından önemlidir. Gıda etiketlerinde gıda katk1 maddeleriyle ilgili bilgilendirmeler bulunmaktadır. Bu etiketler hakkında tüketicilerin de bilinçlendirilmesi gerekir. Tüm dünyada olduğu gibi Türkiye'de gıda sanayinin gelişmesi ile tüketicilerin çok fazla hazır gıda ile karşı karşıya kalması ve tüketilen gidalar hakkında yeterli bilgiye sahip olunmamasından dolayı tüketicilerin uzman kişiler tarafindan bilgilendirilmesi önemlidir. $\mathrm{Bu}$ katk1 maddelerinin yönetmeliklerde izin verilen dozların üzerinde kullanılması ya da istenilen özelliklere sahip olmaması; insan sağlığını tehdit edebilecek en önemli etkenlerden biridir.

\section{KAYNAKLAR}

1. Kaptan B, Kayisoglu S. Consumers' attitude towards food additives. American Journal of Food Science and Nutrition Research. 2015;2(2):21-25.

2. Aksoydan E. Gıda Katkı Maddeleri ve İnsan Sağlığına Etkiler. İstanbul: Mikado Yayınları;2012.

3. Türk Gıda Kodeksi Gıda Katkı Maddeleri Yönetmeliği.www.resmigazete.gov.tr. Erişim Tarihi:30 Haziran 2013.

4. Altuğ T. Gıda Katkı Maddeleri. 2.Baskı. İzmir: Sidas Yayınlar1;2009.

5. Food Additives:

http://www.eufic.org/en/whats-infood/article/food-additive. Accessed March $15,2018$.

6. Food Addivites- World Health Organization. htpp://www.who.int/mediacentre/factsheets/f ood-additives/en. Accessed February 20,2018.

7. Artık N, Şanlıer N, Sezgin AC. Gıda Güvenliği ve Gıda Mevzuatı. Ankara: Detay Yayınc1lik;2019.

8. Elmalı M, Gıda katkı maddelerinin kullanımı ile ilgili kuruluşlar, yasal düzenlemeler ve uluslararası düzenlemeler. Turkiye Klinikleri J Food Hyg Technol-Special Topics. 2016;2(2):11-17.

9. Yörük NG, Danyer E. Gıda katkı maddeleri genel bilgiler ve tanımlar. Turkiye Klinikleri J Food Hyg Technol-Special opics.2016;2(2);1-10.

10. Yurttagül M, Ayaz A. Katk1 Maddeleri: Yanlışlar ve Doğrular, Hacettepe Üniversitesi, Ankara:2008.

11. Biçer $Y$, Uçar G. Gıda katkı maddeleri ve raf ömrü ilişkisi. Turkiye Klinikleri J Food Hyg Technol-Special Topics. 2016;2(2):30-9.

12. Erkan T. Gıdalardaki katkı maddeleri. Türk Pediatri Arşivi. 2010; 45:315-318. 
13. Boğa A, Binokay S. Gida katkı maddeleri ve sağlığımıza etkileri. Arşiv Kaynak Tarama Dergisi. 2010;19:141-154.

14. Erkmen O. Gida kaynaklı tehlikeler ve güvenli gıda üretimi. Çocuk Sağliğl ve Hastalıkları Dergisi. 2010;53(3):220-235.

15. Conlon MA, Bird AR. The impact of diet and lifestyle on gut microbiota and human health. Nutrients. 2015;7(1):17-44.

16. Cani P, Everard A. Talking microbes: when gut bacteria interact with diet and host organs. Mol Nutr Food Res. 2016;60(1):5866.

17. Chassaing B, Koren O, Goodrich JK, et al. Dietary emulsifiers impact the Mouse gut microbiota promoting colitis and metabolic syndrome. Nature. 2015;519(7541):92-96.

18. Cowan TE, Palmnas $M$, Reimer $R$, et al. Artifical sweetener consumpption differentially affects the gut microbiota-host metabolic interactions. The FASEB journal.2013;27(1):224-227.

19. Candan T, Bağdatlı A. Et ürünlerinde nitrit/nitrat azaltılmasına yönelik doğal uygulamalar. Pamukkale Univ Muh Bilim Derg. 2018;24(7):1382-1387.

20. Prasad, S, Chetty, AA. Nitrate-N determination in leafy vegetables: Study of the effects of cooking and freezing. Food Chemistry.2008;106:772-780.

21. Tayfur M. A'dan Z'ye Gida Katk1 Maddeleri. 2.Bask1. Ankara: Detay Yayınc1lı;2017.

22. Skypala IJ, Williams M, Reeves L, Meyer R, Venter C. Sensitivity to food additives, vasoactive amines and salicylates: a review of the evidence. Clin Transl Allergy. 2015;5(34):211.

23. Stevens LJ, Kuczek T, Burgess J, Stochelski MA, Arnold LE, Galland L. Mechanisms of behavioral, atopic, and other reactions to artificial food colors in children. NUTR REV.2013;71(5):268-281.

24. Bingöl EB, Akkaya E, Çolak H. Gıdalarda duyusal özellikler ve gida katkı maddeleri. Turkiye Klinikleri J Food Hyg TechnolSpecial Topics. 2016;2(2):40-50.

25. Maluly HD, Arisseto-Bragotto AP, Reyes FG. Monosodium glutamate as a tool to reduce sodium in foodstuffs: Technological and safety aspects. Food Sci Nutr. 2017;5(6):1039-1048.

26. Fujimoto M, Tsuneyma K, Nakanishi Y, et al. A dietary restriction influences the progression but not the initiation of MSGInduced nonalcoholic steatohepatitis. $\mathrm{J} \mathrm{Med}$ Food, 2014, 17(3):374-383. 